Lexis Vol. XLV (1) 2021: 227-261

\title{
Los riesgos de una lingüística desmemoriada: a propósito de la etimología puquina de $<$ inca $>$
}

\author{
Rodolfo Cerrón-Palomino \\ https://orcid.org/0000-0002-8576-8021 \\ Pontificia Universidad Católica del Perú \\ rcerron@pucp.pe
}

"Y principiando del nombre Inca, es de saber que en
la persona real significa Rey o Emperador, y en los de
su linaje quiere dezir hombre de la sangre real, que
el nombre Inca pertenecía a todos ellos con la dife-
rencia dicha, pero havían de ser descendientes por la
línea masculina y no por la femenina" Garcilaso Inca
([1609] 1943: I, XXVI, 60, énfasis agregado).

\section{RESUMEN}

En el presente artículo quisiéramos proponer la filiación originariamente puquina del nombre <inca>, cuya "biografía" fue retocada sucesivamente por el aimara, el quechua y el castellano, con una serie de ajustes y reajustes formales y semánticos, como resultado de reacomodos idiomáticos sufridos tanto espontánea como deliberadamente. En función de ello, y luego de ofrecer algunos antecedentes sobre el tema, nuestra discusión está organizada en dos grandes secciones: en la primera ofreceremos la etimología del término en forma y significado, postulando su filiación prístina puquina; en la segunda, someteremos a examen y discusión minuciosa la tesis recientemente postulada por César Itier (2019), consistente en atribuirle al término un origen quechua. Demostraremos que la propuesta ofrecida por el colega carece de sustento lingüístico y filológico, 
constituyendo una prueba de cómo la adhesión a la tesis del "quechuismo primitivo" (Cerrón-Palomino 2019) puede conducir a conclusiones realmente insostenibles no solo desde el punto de vista puramente lingüístico, sino, también, y de modo más dramático, en sus proyecciones interpretativas respecto de las instituciones sociopolíticas y organizativas del incario. Palabras clave: inca, filología andina, etimología, morfo vacío, puquina

The risks of a "forgetful" linguistics: on the puquina etymology of $<$ inca $>$

\section{Abstract}

In this article, I would like to propose the original Puquina affiliation of the name <inca>, a term that was successively adopted by Aymara, Quechua, and Spanish, going through a series of formal and semantic adjustments and readjustments, as a consequence of persistent idiomatic re-accommodations, both spontaneous and deliberate. After offering some background on the subject, my discussion is organized into two detailed sections: in the first, I will offer the etymology of the term in form and meaning, proposing its pristine Puquina affiliation; in the second, I will thoroughly examine and discuss the thesis recently propounded by César Itier (2019), in which he attributes a Quechua origin to the term. I will demonstrate that the proposal put forward by my colleague lacks linguistic and philological support, proving how adherence to the thesis of the so-called "Quechuismo primitivo" (Cerrón-Palomino 2019) can lead to truly unsustainable conclusions not only from a purely linguistic point of view but also, and in a more dramatic way, from its purported interpretative projections regarding the socio-political and organizational Inca institutions.

Keywords: inca, Andean philology, etymology, empty-morph, Puquina 


\section{Antecedentes}

Tras las primeras tentativas por designar al soberano cuzqueño en el temprano contacto de 1532 en Cajamarca, refiriéndose a él como "el Cuzco", confundiendo el topónimo con el antropónimo, ${ }^{1}$ los españoles pronto caerán en la cuenta de que el título del dignatario era en verdad inga, según les pareció escuchar de labios de su gente. Y así, el sobrenombre adquiriría carta de ciudadanía en el habla de los conquistadores para ser registrado como $<$ ynga $>$ por los cronistas poco tiempo después. La designación, en la forma registrada (y pronunciada), prevalecerá a lo largo del siglo XVI, pero será objeto de fijación y normalización por el Tercer Concilio Limense ([15841585] 1985) bajo la forma de <inca $>$, la misma que irá imponiéndose definitivamente en el trascurso de la siguiente centuria. La pronunciación previa del nombre, con sonorización de su consonante tras nasal, propia de la "lengua general", será recusada como "corrupta" por los quechuistas del sínodo limeño (Cerrón-Palomino 2013b: III, $\mathbb{2}$ ), del mismo modo en que lo serán todos los términos con oclusiva sonorizada tras nasal, consignados por el primer gramático y lexicógrafo del quechua, el dominico fray Domingo de Santo Tomás ([1560] 1994a, [1560] 1994b), quien, sin embargo, no registra aún en su obra el nombre que nos ocupa. De manera elocuente, el Inca Garcilaso, fiel seguidor de los postulados ortográficos implícitos del Concilio Tercero, cambiará a partir de 1590 su sobrenombre de $<$ Inga $>$, que ostentaba orgullosamente, por el de $<$ Inca $>$ (Cerrón-Palomino 2013b: III, $\mathbb{~} 3$ ). ${ }^{2}$ Consecuente con la fijación del nombre <inca>, el tratado gramatical y léxico propiciado por

\footnotetext{
1 Ello ocurre entre los cronistas de las "relaciones primitivas" de la conquista, en las que "el Cuzco viejo" hace referencia a Huaina Cápac, en oposición al "Cuzco joven”, que vendría a ser Huáscar o Atahualpa (ver, por ejemplo, Sancho de la Hoz [1534] 1968: 282).

2 Con todo, en el "Tratado" sobre los “errores y svpersticiones de los Indios", del Licenciado Polo Ondegardo (1559), que los traductores del sínodo limeño insertan en el "Confessionario" (Tercer Concilio [1584-1585] 1985: 265-283), se respeta el uso de $<y n g a>$, propio de su tiempo, en los escritos del conocido averiguador de antiguallas incaicas.
} 
el sínodo lo registrará como <ynca> (Anónimo [1586] 2014: 116), del mismo modo en que lo hará más tarde el primer codificador del quechua cuzqueño (Gonçález Holguín [1608] 1952: 368), siguiendo en esto al autor anónimo, que todo indica que fue nada menos que Blas Valera. No obstante la pauta ortográfica consagrada en tales tratados lexicográficos, cronistas indios como Guaman Poma y Pachacuti Yamqui Salcamayhua usarán todavía tanto <ynga> como $<$ ynca $>$, de modo alterno, bien entrada la segunda década del siglo XVII. Son los últimos estertores registrales de $<$ ynga $>$ $<$ inga $>$ que en adelante quedarán como reliquias ortográficas. De esta manera, consolidada y legitimada la forma <inca $>$ por la práctica escrituraria, se instalará definitivamente, dentro de la tradición historiográfica incaica, libre de todo cuestionamiento ortográfico o formal, aun cuando se discuta ocasionalmente, en el plano de su significación, el carácter arbitrario de su ecuación semántica con nombres castellanos como "rey" o "soberano".

\section{Etimología de <inca $>$}

Que sepamos, nadie puso en tela de juicio el origen quechua de $<$ inca >, excepto tal vez, y de pasada, Alfredo Torero (1994), quien solía andar algo errático en sus etimologías, cuando ensaya, sin mayor elaboración, el antropónimo de linaje nativo <yanqui> $<$ yamque $>$ como posible étimo aimaraico de $<$ inca $>$. En otro lugar ya nos referimos a dicha propuesta, demostrando su inviabilidad no solo lingüística sino también documental (Cerrón-Palomino 2013a: 38), de manera que aquí ya no volveremos sobre el asunto. Debemos señalar sí, que en un trabajo anterior (Cerrón-Palomino 1997: nota 17) y en el citado previamente (Cerrón-Palomino 2013b: nota 17), adelantamos la hipótesis de que, no siendo posible adscribirle un entronque aimara o quechua, no era aventurado sostener que tuviera filiación puquina. Nos basábamos para ello no solo en el dato temprano recogido por Uhle en sus trabajos de campo, cuando refiere que en Sicuani "se dice todavía” <Enqa>, según afirma haberlo escuchado pronunciar a los lugareños (Uhle [1910] 1969: 
68, nota 114), sino también en el registro léxico de las variantes $<$ enqachu $>\sim$ <enqaychu $>$, propias del lenguaje ritual de los pobladores de las sierra alta del Cuzco (Flores Ochoa 1977, 2002), en las que no es difícil aislar el elemento <enqa> encontrado por el fundador de la arqueología andina, justamente en zonas aledañas a las mencionadas por el antropólogo cuzqueño. Pues bien, en los párrafos siguientes trataremos de afianzar dicha hipótesis aportando nuevos datos sobre la materia, esta vez de naturaleza documental y etnográfica.

En cuanto a la información documental, si bien indirecta y relativamente tardía, esta proviene de dos fuentes: de la Nueva Coronica de Guaman Poma ([1615] 1936) y del Libro $2^{\circ}$ de las Memorias antiguas de Montesinos (1644; Szemiñski 2009). Por lo que toca a la primera, ocurre que el cronista lucaneño desliza la forma $<$ enga $>$, contra su práctica preferida de escribir $<$ ynga $>0<$ ynca $>$, en una de las “ordenansas” de Tupa Inca Yupanqui, que dice así:

yten mandamos en este nuestro rreyno que nenguna persona blasfemie al sol mi padre y a la luna mi madre y a las estrellas y al luzero chasca cuyllor uaca billcaconas y a los dioses guacas y que no me blasfemie a mi mismo y enga y a la coya (Guaman Poma [1615] 1936: 185, énfasis agregado).

Al respecto, bien puede ponerse en tela de juicio la naturaleza de la notación: podría tratarse, en efecto, de una simple "errata" por <ynga>, como lo sostiene el maestro Carlos Araníbar ([1615] 2015: nota 562); tampoco es imposible que pasara como un "mote", producto de la habitual confusión del autor de las vocales /i, e/ del castellano, en este caso frente a una palabra ya incorporada plenamente a esta lengua. Sin embargo, no es descartable del todo que, como dijimos, se haya filtrado un uso alternante del término, corriente aún en labios de los quechua-hablantes, y que, por consiguiente, mantuviera aún la evidencia indirecta de la antigua presencia de una /q/ que estimulara la apertura vocálica concomitante. Así lo parece entender también el etnógrafo polaco Szemiñski, si bien sin entrar en detalles sobre el asunto (Szemiñski 2009: 28). Es más, al 
mismo estudioso le debemos también la interpretación de <enqa> en dos pasajes mal copiados del escriba responsable del manuscrito de la versión sevillana de Montesinos que edita. En la lista de los cien monarcas que ofrece el fantasioso cronista, encuentra el editor dos veces la lectura aparentemente sinsentido de $<$ enlarroca $>$, que él interpreta, correctamente a nuestro modo de ver, como una lectura errática del traslado del manuscrito del texto sevillano, y en el que <enCarroca> se habría leído mal en favor del entuerto mencionado (con copia de $<\mathrm{C}>$ como si fuera $<\mathrm{l}>$; Szemiñski 2009: 28). ${ }^{3}$ Pues bien, por muy ambiguas y discutibles que fueran estas dos referencias documentales, no descartamos que ellas se vean sustanciadas por el dato ofrecido por Uhle, y más aun por la evidencia etnográfica aportada por Flores Ochoa que examinaremos en seguida.

En varios de sus trabajos de corte etnográfico, y más precisamente en los relacionados con la religiosidad andina de los pueblos de altura de las provincias sureñas del Cuzco, Flores Ochoa describe los ritos y ceremonias de los pastores de camélidos consistentes en la invocación de seres abstractos y sobrenaturales en los que intervienen, aparte de la <illa $>$, el $<$ enqa $>$, el $<$ enqaychu $>$ y la $<$ khuya rumi $>$ [sic], materializados simbólicamente como mediadores entre lo divino y humano en la forma de piedra pulida redonda u ovoidea, de diverso tamaño, entre las cuales la principal de ellas es el <enqa> (Flores 1977, 2002). Considerado como el intermediario de mayor jerarquía, el <enqa> es "el principio generador vital”, "la fuente y el origen de la felicidad, el bienestar”, así como el propiciador de la abundancia del ganado. Sin <enqa>, enfatiza el autor, "no hay posibilidad de éxito para la familia, ni que el ganado prospere y pueda así conceder bienestar a sus dueños” (Flores 1977: 218); y

\footnotetext{
3 No está de más señalar que son conocidas nuestras discrepancias con las interpretaciones filológicas, a menudo fantasiosas, que suele proponer el estudioso polaco en materia de onomástica andina. Sin embargo, a diferencia de él, quien nunca cita ni comenta nuestros trabajos, no consideramos un desdoro reconocer aciertos en algunas de sus propuestas cuando ellos se dan, según lo hemos declarado en otras publicaciones previas a la presente. De paso, sospechamos que piezas de evidencia como las aportadas indujeron a Szemiñski a abjurar de su práctica de escribir <inka $>$ para optar en adelante por <inqa>, decisión que el autor, que sepamos, no llega a precisar en sus escritos.
} 
son precisamente estas facultades divinas atribuidas al <enqa> las que son invocadas por los pastores en sus plegarias. $\mathrm{El}<$ enqaychu>, consistente en "pedruzcos de color claro y oscuro", tiene también el mismo poder de <enqa> (Flores 2002: 616); y la <khuya rumi>, "una losa de color claro", tiene igualmente dotes de "protectora y generosa” (Flores 1977: 234). Estas piedras se encuentran en las lagunas y páramos de los glaciares; de allí, según los informantes de Flores Ochoa, "vinieron los enqa o los enqaycho" (Flores 1977: 220).

Pues bien, lo que advertimos en Flores Ochoa, concretamente en el lapso transcurrido entre la redacción de su artículo de 1977 y la del de 2002, es su convicción final en sostener que en verdad el $<$ enqa > y el <enqaychu>, seres abstractos y poderosos, tal como se desprende de los testimonios recogidos de labios de los pastores, no serían sino representaciones simbólicas de los incas del pasado remoto, "así en plural, puesto que da a entender que los antiguos reyes estaban en esta categoría, debido a sus características divinas” (Flores 2002: 616). Lo que el autor pierde de vista, sin embargo, es que su $<$ khuya rumi $>$, que para él no pasa de ser una simple divinidad protectora, es en verdad falsa etimología de <quya rumi>, es decir la piedra que simboliza a la <coya $>$, la esposa del inca. Creemos en este caso que la palabra responsable de la distracción etimológica del investigador, y de la de sus informantes, fue la falsa asociación del término < coya> con el verbo khuya- 'querer, amar', 4 que obviamente como calificativo de rumi 'piedra' no tiene mucho sentido, y en cambio distrae y aleja de su valor simbólico auténtico: el de la mujer del inca. Dos ingredientes más deben tomarse en cuenta en la retórica mágico-religiosa de los pastores de altura, según nuestro parecer: que las piedras que encarnan el poder divino se encuentran en las lagunas de altura, por un lado, y por otro, que

\footnotetext{
4 No debe sorprender que esta falsa relación con el verbo mencionado pueda estar motivada por uno de los atributos conocidos de los incas, tal como nos lo recuerdan los cronistas, en especial el Inca Garcilaso de la Vega, para quien los soberanos cuzqueños eran llamados < huaccha cuyac>, es decir /wakcha khuyaq/ 'curador, o protector de los desvalidos y desamparados'.
} 
las plegarias de los ganaderos tienen pasajes que parecen haber sido entresacados de las preces registradas por el cronista de la Relación de las fábulas y ritos de los incas (Molina [1575] 2021). Todo ello abona en favor, sin duda alguna, de la identificación del <enqa> con el <inca>, que emerge de las aguas del Titicaca según los mitos de origen, y que es objeto, como ser divino, de las oraciones consignadas por el cronista Molina (Oraçion por ynga, fol. 16r y Oraçion por todos los yngas, fol. 16v; para la interpretación y traducción de los mismos, ver Cerrón-Palomino 2021a).

Conviene ahora explicar la diferencia formal entre <enqa $>$ y $<$ enqaychu $>$. Ya se dijo que ambos términos comparten el radical aislable de <enqa>, debiendo darse cuenta en seguida del parcial <-ychu>, que no parece sufijo asignable a ninguna de las tres lenguas generales del antiguo Perú. Ahora bien, lo interesante es que, según dato aportado por los compiladores del Diccionario quechua-español/ español-quechua, <enqaychu> varía con <enqayllu> (AMLQ 1995: 122). Esta última variante conduce, a nuestro modo de ver, a la solución del problema entrevisto, en la medida en que ahora resulta que la primera variante puede ser explicada de manera natural a partir de la segunda. En efecto, si asumimos que <enqa-yllu> es voz contraída de *<enqa ayllu> 'linaje de los incas', entonces <enqa-ychu> se explicaría como una variante que acusa sustrato puquina, en vista de la fluctuación entre /ll/ y /ch/ propia de esta lengua (Cerrón-Palomino 2020: \$7.1.1.4), descartándose al mismo tiempo la existencia del aparente sufijo distractor. ${ }^{5}$ En fin, tras las razones expuestas hasta aquí no parece haber duda de que, en efecto, <enqa> es la forma fosilizada del término institucionalizado dentro de la historiografía andina como <inca $>$. No debiera sorprender que la palabra, en su versión prístina, se haya

\footnotetext{
5 De paso, creemos que el mismo fenómeno de contracción puede ayudarnos ahora con el análisis de la palabra <zumbayllu>, la peonza que tanto maravillaba al niño Arguedas, según nos cuenta en sus Ríos profundos (Arguedas 1983: cap. VI). En el presente caso, el parcial <-yllu>, cuya etimología extravió al novelista, no es sino lo que queda de la contracción de <zumba ayllu(q)>, donde el <ayllu > alude al cordel como envoltorio del trompo.
} 
refugiado en el lenguaje mágico-religioso empleado por los pastores de la región altoandina del Cuzco, sucumbiendo ante su versión normalizada y consagrada por escrito desde la segunda mitad del siglo XVI. ${ }^{6}$

Pues bien, basados en la evidencia documental y etnográfica discutida, creemos estar ahora en condiciones de postular *enqa como el étimo del término institucionalizado <inca >, voz de origen puquina y no quechua ni menos aimara. ${ }^{7}$ Queda entonces por intentar explicar cómo es que esta versión normalizada y oficializada sustituye a su versión primigenia. Para ello, conviene traer a cuento la forma en que la palabra es registrada en las fuentes documentales tempranas, como por ejemplo en las crónicas de Betanzos ([1551] 2015), Cieza ([1551] 1985), o la de Zárate ([1555] 1995); y lo que encontramos allí es $<$ ynga $>$, y por más señas se habla de "la lengua del ynga", llamada poco después "lengua general", que es la que describe por primera vez el Nebrija indiano, es decir fray Domingo de Santo Tomás ([1560] 1994a, [1560] 1994b). Y aun cuando el dominico no registra la palabra ni en su lexicón ni en su gramática, no es difícil darse cuenta de que formas con rasgos parecidos a los de <ynga $>$ asoman con frecuencia en sus escritos, como cuando consigna < <inga $>$ 'nariz', < conga-> 'olvidar', < songon $>$ 'entrañas', etc. El común denominador de estos ejemplos es que ellos muestran sonorización de consonante, en este caso $<\mathrm{g}>$ tras nasal. Como se sabe, sin embargo, el rasgo en cuestión no estaba generalizado, pues por ejemplo no se registra en el nombre < pinca-> 'avergonzar'. En verdad, el fenómeno afectaba a todas las consonantes oclusivas tras

\footnotetext{
6 Asombra pensar que nuestro colega Itier le restara toda atención a un dato etnográfico tan importante proporcionado por Flores Ochoa, él que suele apoyarse en informaciones de fuente oral tradicional, aunque casi siempre idiolectales y anecdóticas, provenientes de sus informantes andahuailinos, como lo hace en el trabajo que discutimos.

7 Un dato igualmente revelador que apunta en la misma dirección etimológica postulada es el hecho de que la lengua amuesha, de la familia arahuaca de la región centro-amazónica y colindante con los pueblos de habla quechua de los Andes centrales, haya incorporado en su léxico un caudal considerable de voces quechuas, entre ellas nada menos que la palabra de origen puquina estudiada, en la forma de <enka>, con el significado de "rey" (Adelaar 2006: 290).
} 
nasal, y este era precisamente el atributo característico de la "lengua del ynga” (Cerrón-Palomino 2017), una especie de koiné considerada como la variedad oficial del imperio. ${ }^{8}$

Ahora bien, si asumimos que la forma fonética aproximada del término, apoyados en su versión actual fosilizada, es [enqa], equiparable a la de voces comunes como [senqa] 'nariz' y [p'enqa-] 'avergonzar', no es difícil advertir otro fenómeno fonético propio del quechua en su conjunto, consistente en la apertura de las vocales en contacto directo o indirecto de una postvelar /q/, tanto que una de las reglas prácticas invocadas por los estudiosos de la lengua para interpretarlas en los registros coloniales es justamente apelar a dicha "prueba vocálica”, para saber si funcionalmente se está ante /i, e/ o /u, o/. Aplicada esta regla a los registros de los jesuitas Blas Valera (Anónimo [1586] 2014) y Gonçález Holguín ([1608] 1952), veremos que coinciden en registrar $<$ cenca $>$ y $<$ penca- $>$ el primero; $\mathrm{y}<$ cencca $>\mathrm{y}<$ ppencca- $>$ el segundo, con mayor precisión fonética del consonantismo, propia del quechua cuzqueño que describe. Ambos, sin embargo, coinciden en consignar $<$ ynca $>$, y no *<enca $>$ o *<encca>, como se habría esperado.

¿Cómo explicar entonces las diferencias en la notación de los términos presentados? Ante todo, hay que decir que los dialectos descritos no son los mismos: Domingo de Santo Tomás describe lo que él llama "lengua general”, a la par que el Anónimo registra la variedad quechua normalizada por el Tercer Concilio Limense, mientras que Gonçález Holguín se aboca a compilar y consignar el dialecto cuzqueño de su época. Las diferencias tienen que ver, una vez más, con los efectos del fonema /q/ sobre las vocales aledañas, que se "abren" cuando entran en vecindad con él. Ocurre que, en este caso, estamos hablando de un contacto indirecto, ya que entre la vocal y la consonante está de por medio la nasal; y en este

\footnotetext{
8 Para el colega César Itier, cuya propuesta etimológica de <inca > comentaremos más adelante, dicho rasgo habría correspondido a la "variedad de quechua antiguamente hablada en el Cuzco". Se trata de una tesis que viene sosteniendo el autor en sus escritos recientes sin proporcionarnos evidencia empíricamente convincente en favor de la procedencia dialectal asumida.
} 
contexto los efectos abridores de la postvelar no son tan potentes como cuando ella se muestra en contacto directo con la vocal afectada. No debe extrañar entonces que la vocal /i/ de [enqa] pudo ser interpretada como una intermedia entre /i/ y /e/ por el oído español, de manera que se escuchase [Inqa] y se escribiese <ynga> y no *<enga>. ${ }^{9}$ Añádase a esto el hecho de que el fenómeno de sonorización tras nasal, propio de la "lengua general”, mitigó de alguna manera, neutralizando o confundiendo, la oposición entre los puntos velar y postvelar (es decir / k/ versus /q/). De este modo, estaban dadas las condiciones para que $<$ ynga $>$ pudiera ser interpretada no como *<yncca $>$ sino como $<$ ynca $>$.

Pues bien, los tratadistas del Tercer Concilio Limense ([15841585] 1985) fueron quienes, al sentar las pautas ortográficas del quechua que codifican, optando por una variedad de base cuzqueña, recusan todo rasgo sonorizante de la lengua general, por considerarla implícitamente "corrupta” (Cerrón-Palomino 2017: \$ 3). De esta manera, <ynca > es la forma normalizada y oficializada por los quechuistas del sínodo mencionado. ${ }^{10} \mathrm{Y}$ es esta postura normativista, apoyada en una percepción deficitaria de los fenómenos mencionados (sonorización consonántica neutralizadora de la oposición velar-postvelar), la que indujo a que <ynga $>$ se normalizara como <inca>, una “restitución”, como se ve, erráticamente "purista”, pero con fortuna asegurada en adelante. ${ }^{11}$

\footnotetext{
9 Para un estudio sistemático de la conducta de las vocales quechuas en general (y en contacto con la postvelar en particular) efectuado mediante el empleo de carta de formantes, y que demuestra la gran versatilidad de las realizaciones de /i, u/ en el contexto de postvelar, deslizándose en el eje vertical dentro de un amplio campo de dispersión, ver el estupendo trabajo de Pérez Silva (2011).

10 Ello explica suficientemente la extrañeza de Itier, en su objeción del étimo *inqa, en el sentido de no encontrarse, en las fuentes antiguas que distinguen /k/ y /q/, formas como <incca> o <encca>, que se esperarían si la voz originaria hubiese sido /inqa/ (2019: 136).

11 Un término indudablemente relacionado con inqa, y que al mismo tiempo corrobora la etimología propuesta, es el de <yñaca $>$ o <iñaca $>$, que el dominico da como equivalente de <palla> (Santo Tomás [1560] 1994b: 159: “dama, es casi señora”) o de $<$ nusta $>$, según el aimarista italiano (Bertonio [1612] 1984: 325: “muger noble del Cuzco”), tal como ya lo habíamos sugerido en Cerrón-Palomino (2013a: I-2, § 3.1.12). Lejos de considerar a las "damas iñaca” como una categoría social especial, como lo hace Zuidema (2010: cap. 6, \$3.2), confundiendo, como era habitual en él en casos semejantes, entre
} 


\section{La hipótesis de Itier}

En esta sección, tal como fuera anunciado, examinaremos la etimología reciente del colega francés del término <inca>, que para él tendría filiación quechua. Demostraremos que su propuesta no tiene asidero ni lingüístico ni filológico ni menos histórico, como él supone, ya que parte de un grave error interpretativo, analítico y conceptual, del material quechua analizado; y, como consecuencia de ello, todo el esfuerzo de interpretación del significado del término y las revisiones de orden socio-político e histórico que el autor propone, en función de lo que él considera una alternativa de comprensión más certera y novedosa del concepto analizado, resultan en un extenso discurso retórico, que, a lo sumo, siendo complacientes, diríamos que de ningún modo fluye de la postulación etimológica propugnada. En tal sentido, nos adelantamos en señalar que aquí nos interesa, concretamente, rebatir la hipótesis etimológica sostenida, pues una vez conseguido ello, como se verá, la propuesta revisionista de la historiografía incaica reclamada por el autor cae por su propio peso, desprovista de todo empirismo elemental reclamado por la ciencia lingüística y filológica. ${ }^{12}$

\footnotetext{
$<$ ỹ̃aca $>$ y < ñañaca $>$ 'mantellina' (ver la nota 35 de nuestro trabajo citado), estamos convencidos de que <iñaca>, escrita a veces como <inaca>, es decir /inaqa/, no sería sino una forma epentetizada de <inca>. En tal sentido, el término no aludiría sino al linaje propio instituido por Pachacutiy, tal como se desprende de la carta de los descendientes de los incas que el Inca Garcilaso reproduce en el último capítulo de sus Comentarios, y en la que se dice que a "la descendencia del Inca Pachacutec [...] llaman Inca Panaca" (Garcilaso [1609] 1943: 296, énfasis agregado). Claramente, el silencio total del ilustre cronista respecto de esta palabra, que le habría parecido "impertinente", nos sugiere que no habría tal institución especial llamada <iñaca >. Lo que ocurrió seguramente es que la forma epentetizada de <inca $>$ fue interpretada por el investigador holandés mencionado y por los historiadores modernos como una categoría social especial, aunque de origen ciertamente hechizo.

12 En la nota 2 del artículo comentado el colega Itier (2019) rechaza la propuesta que adelantáramos en favor de *inqa como étimo de <inca $>$, aduciendo que no encuentra “justificación [para] identificar <inga $><$ inca $>$ como /inqa/", puesto que no presento evidencias "de una continuidad semántica entre la noción de principio generador y el antiguo concepto sociopolítico de 'inga”". Sobra decir que en la nota 18 de CerrónPalomino (2008: 339), dado su carácter incidental, no podíamos presentar mayores argumentos que los aportados, fuera de apoyarnos en las referencias hechas allí, especial-
} 


\subsection{Propuesta etimológica}

La proposición etimológica del colega francés está desarrollada en la sección 10 del trabajo citado, bajo el rubro de "Significado de inka en el siglo XVI". Se pregunta el autor si la palabra <inca> "era el nombre "propio», es decir opaco, de una institución sociopolítica o si tenía un significado susceptible de extraerse del análisis de diferentes empleos del término con referentes diversos" (Itier 2019: 146).

Pues bien, notemos, en primer lugar, el uso del adjetivo "opaco" para calificar <inca> como término institucional de corte sociopolítico, lo que ya nos parece un claro ejemplo de petición de principio. Como fuese, el hecho es que la anunciada opacidad vendría a ser el motivo que impulsa al investigador a buscar "diferentes empleos del término con referentes diversos". No se necesita mayor perspicacia para advertir que lo que se tenía en mente, para ser invocado como "referente diverso" (tomado como verdadero "anillo al dedo"), era precisamente el conocido sufijo distributivo quechua $<$-inca $>\sim<$-incanca $>$, usado en las expresiones adverbiales numerales, y cuya forma tiene el símil ilusorio, como veremos, de aparentar ser idéntica a la palabra que nos ocupa. Y así echa mano de los datos proporcionados al respecto por el primer gramático quechua. Sin tomarse el trabajo de evaluar las reglas que el sevillano proporciona en su gramática para el recto empleo del sufijo en cuestión (Santo Tomás [1560] 1995: 123-127), opta de inmediato por el elemento postpuesto, en su variante <inca>, para asociarlo con la raíz léxica <inca>; y no contento con ello, interpreta la otra variante $<$-incanca $>$ como una reduplicación de *inca-inca $>$, en versión apocopada, ${ }^{13}$ para darle el valor de colectividad buscado de

mente en la noticia interesante ofrecida por Uhle, pero ninguneada de golpe por nuestro crítico. Sobra señalar que esta es, precisamente, la oportunidad que el autor nos brinda para atender los reclamos que echaba de menos.

13 Sostener que <incanca $>$ es una forma reduplicada y sincopada de *<inca-inca $>$ es un error desde el momento en que dicho sufijo debe analizarse, previa segmentación correcta, como una versión reforzada de $-n k a-n k a$, donde en todo caso la reduplicación sería copia del sufijo - nka. A nuestro modo de ver, sin embargo, todo indica que el ope- 
antemano. De este modo, llegará a sostener que en verdad el significado de <inca> habría tenido "una acepción especializada $-\mathrm{y}$ probablemente históricamente secundaria- del significado fundamental de '(algo o alguien) separado'” (Itier 2019: 149). Vemos aquí extrapolado y acomodado, de manera forzada, el significado distributivo y adjudicativo a la vez del sufijo quechua mencionado, con el objeto de justificar su alternativa, fallida diríamos, de interpretación semántica del nombre estudiado. En lo que sigue nos detendremos en el examen del análisis desacertado en el que incurre el autor respecto del elemento gramatical que él considera “cognado" del radical léxico <inca $>$.

\subsection{Examen de la propuesta}

Partiremos para ello primeramente del mismo material con que el dominico ilustra el funcionamiento del sistema numeral distributivo del quechua que describe, luego veremos el tratamiento del mismo fenómeno por parte del jesuita Gonçález Holguín, para después someter a prueba las descripciones ofrecidas siguiendo los procedimientos de análisis morfológico contemporáneos que nos ofrece la disciplina. Pues bien, según el primer gramático de la lengua, el morfema empleado para expresar cantidad de objetos que deben ser distribuidos separadamente según lo expresado por el numeral al que se yuxtapone, tendría dos manifestaciones básicas: <incanca> e $<$ inca $>$, de manera que <quimça incanca $>$, o simplemente <quimça inca $>$, significaría, distributivamente, 'a cada uno tres'. La segunda forma le parece más elegante y económica que la primera, pues nos dice que <inca> "es término más polido y más breve y haze el mismo sentido, v. gr.: 'a cada uno siete' diremos canchiz inca o incanca, que es lo mismo” (Santo Tomás, [1560] 1995: 126). Una vez presentadas las dos variantes alomórficas, el sevillano ensaya una

rador -nka proviene de una forma subyacente $*-n$-kama, cadena morfológica integrada por la $-n$ ' 3 a . persona' en función partitiva, seguida del sufijo - $k a(m a)$ apocopado, en su valor distributivo. Ello explica la total equivalencia entre, por ejemplo, ishkay-ni-nka e ishkay-ni-n-kama 'a cada uno, dos', expresiones alternantes en el quechua-huanca. 
regla más precisa en cuanto al empleo de un tercer alomorfo, esta vez la sub-variante de $<$ inca $>$, que viene a ser simplemente $<$ nca $>$. Según ella, cuando los numerales "se acaban en consonante", se tiene la forma enteriza, como en <puçac inca> 'a cada uno, ocho', $<$ izcon inca> 'a cada uno, nueve', "porque puçac, que es 'ocho', [e] $i z c o n$, que es 'nueve', se acaban en consonante"; en cambio se tiene <chunganca> 'a cada uno, diez' y <çoctanca> 'a cada uno, seis', "porque chunga, que es 'diez', y çocta, ques 'seis', acaban en vocal" ([1560] 1995: 126-127). Remata el autor confesando que la "razón cierta desta diversidad no la alcanço, mas de que assí se usa en esta lengua" ([1560] 1995: 127). Con todo, en vista de la precisión de la regla, los lingüistas modernos estaríamos casi llanos a suscribirla íntegramente. El hecho es, sin embargo, que el autor elige como norma o base del morfema la forma enteriza $<$ inca $>$, de manera que la expresión <chunganca> 'a cada uno, diez' la explica a partir de *<chunga inca $>$, donde la vocal $<\mathrm{i}>$ del elemento pospuesto, que se contrae en favor de la $<a>$, sería el resultado de una "sinalefa". ${ }^{14}$ Dejando de lado esta interpretación, obsérvese que, en la forma en que lo registra el autor, el morfema en su versión enteriza, o sea $<$ inca $>$ o $<$ incanca $>$, aparece como una postposición, de naturaleza autónoma, y no como un sufijo ligado a su base. Lo cual no debe extrañar en las gramáticas de la época, en las que no solo las postposiciones sino incluso los sufijos se registran a veces por separado (desligando lo inseparable y separando lo indesligable). De paso, es justamente esta práctica descriptiva, que no siempre suele diferenciar entre lo que modernamente llamamos sufijos y postposiciones, la que crea la ilusión gráfica de estar ante elementos autónomos o aislables cuando en verdad se está ante verdaderos sufijos. No queda, pues, duda de que este hecho, unido al establecimiento de

14 Figura que el ilustre gramático explica en estos términos: "quando concurren inmediatamente dos dictiones que no tienen buen sonido, si se proferiessen ambas enteras, y en tal caso o la una o ambas pierden letras, y casi de ambas se haze un término" (Santo Tomás [1560] 1995: 148). Modernamente hablamos en casos como este de contracción vocálica transmorfémica. 
$<$ inca > como norma del morfema, parece haber inducido al colega Itier a tomarlo como "cognado” del elemento léxico <inca $>$.

En cuanto al análisis ofrecido por el jesuita cacereño, diremos que este quechuista sigue al dominico en el establecimiento de la marca numeral distributiva, en la forma autónoma de <ynca>, según se puede ver en ejemplos como <huc yncalla $>$ /huk-inka-lla/ 'de vno en vno', <quinça yncalla> /kinsa inka-lla/ 'de tres en tres' y <chunca yncalla> /chunka inka-lla/ 'de diez en diez' (Gonçález Holguín [1607] 1975: 39-40), y claramente al margen de la regla establecida por el sevillano, a estar por los dos últimos ejemplos. Lo que él hace es, prácticamente, generalizar el empleo de la forma canonizada, es decir <ynca>; y ello se da no solo con los numerales, sino también con otras raíces cuantitativas, como en <assincalla> /aş-i-nka-lla/ 'cada vno un poco', donde < ass > se glosa como 'poco' $\mathrm{y}<-1 \mathrm{la}>$ es el limitativo-afectivo insustituiblemente traducido por el adverbio "nomás" del castellano andino.

Pues bien, ¿qué podemos decir modernamente del estatus del morfema normalizado como <inca $>$ o $<$ ynca $>$, a la luz de su variación con $<$ nca $>$, según el análisis del dominico? ¿Deberíamos aceptar la regla de contracción que sugiere (= sinalefa, en sus términos) para dar cuenta de la alternancia entre la forma enteriza <inca> y su versión recortada $<$ nca $>$ ? ¿Debemos ver también en la forma $<$ incanca $>$ una reduplicación de *<inca-inca $>$, según sostiene Itier? ¿Qué nos dice al respecto la tradición descriptiva quechua moderna respecto no solo de la forma del elemento gramatical sino también de su estatuto como sufijo o postposición, y por consiguiente de su autonomía léxica? En lo que sigue trataremos de responder cada una de estas interrogantes.

\subsection{Morfo vacío <-i>}

Modernamente las expresiones adverbiales numerales distributivas se consideran formadas mediante el elemento -nka, considerado como un sufijo, que se agrega a la raíz numérica o cuantitativa, cuando esta acaba en vocal: así, en tawa-nka 'a cada uno, cuatro', o chunka-nka 'a cada uno, diez'; cuando, sin embargo, la base 
termina en consonante se tiene iskay-ni-nka 'a cada uno, dos', o isqun-ni-nka 'a cada uno, nueve', etc. En todos estos casos, como se aprecia, no aparece la variante colonial <inca> tras consonante, pues en su lugar lo hace el morfema que acabamos de identificar, es decir $-n k a$, con el auxilio del estribo - ni para poder engarzarse a la base. Este elemento, conocido tradicionalmente dentro de la lingüística quechua como "morfo vacío", juega un rol importante en todos los dialectos modernos del quechua, como un linker, socorrido no solo para satisfacer la estructura silábica de la expresión derivada en cuestión sino también por razones puramente eufónicas (Cerrón-Palomino 2008a: cap. II, \$2.4). Se ve claramente entonces que allí donde estaba la $<$ i $>$ de $<$ inca $>$ aparece ahora el morfo vacío -ni. De hecho, la evidencia documental prueba que el recurso a este conector silábico podía ocupar la posición de $<\mathrm{i}>$, como una alternativa, ya en tiempos de la colonia, como nos lo demuestra el jesuita cacereño, cuando registra, por ejemplo, <huquey $>/$ huk-i-y/ alternando con <hucniy>/huk-ni-y/ 'vno de los míos', <huqueyqui> /huk-i-yki/ o <hucñiyqui> /huk-ñi-yki/ 'vn compañero tuyo'; o, en fin, <huqquen>/huk-i-n/ o <hucnin>/huk-ni-n/ 'el otro su compañero’ (Gonçález Holguín [1608] 1952: 196). Y agréguese a ello el dato importante de cómo para el mismo quechuista y sus informantes, una expresión como <munaquey $>$ /muna-q-i-y/ 'es mas galano modo y mas vsado en el Cuzco', que no <munacnij> /muna-q-ni-y/ ([1608] 1952: fols. 17-17v). ${ }^{15}$

\footnotetext{
15 De manera mucho más incontrovertible, el morfo vacío - $i$ asoma en algunos ejemplos proporcionados por el Anónimo ([1586] 2014), como en <sipasiy> 'mi muchacha', $<y$ ahuariyqui> 'tu sangre', <yahuarin> 'su sangre', que analizamos como /sipas-i-y/, /yawar-i-yki/ y /yawar-i-n/, respectivamente, pues estas dos raíces léxicas, que sepamos, jamás acabaron en vocal; lo propio podemos decir de voces ya lexicalizadas como el topónimo /chaw-i-n/ 'Chavín' (<*⿳亠丷aww-i-n 'su centro') o el lexema /chus-i-q/ 'var. de lechuza' ( $<$ *čus- $i-q$ 'aquel que dice chus'). Sobra decir que los ejemplos no lexicalizados requieren en la actualidad del morfo vacío - ni, como en /sipas-ni-y/, /yawar-ni-yki/ y /yawar-ni-n/, respectivamente. Incidentalmente, en todos estos ejemplos hablamos de la inserción de -ni por razones estructurales; pero el recurso a dicho apoyo también se dio por razones puramente eufónicas; y así, expresiones como <coylloryoc $>$ 'estrellada cosa', <yaguaryoc $>$ 'cosa con sangre' y <sipasyoc $>$ 'amancebado', que encontramos en el Anónimo (1586] 2014), alternando con <coyllornioc >, <yaguarnioc > y <sipasnioc>,
} 
Dicho todo ello, por cierto, al margen de la distracción del jesuita al recurrir a $<\mathrm{q}>$ o $<\mathrm{qq}>$ en lugar de $<\mathrm{c}>$ como correspondía a la palabra para 'uno', es decir /huk/, confundido quizás por las construcciones agentivas como <chayaqquen> /chaya-q-i-n/ 'lo justo', equivalente a <chayaknin>/chaya-q-ni-n/, en las que se justificaba el recurso a la grafía de $<\mathrm{q}>$, aunque, incluso en este caso, el autor vacila al escribir <yalliquin> /yalli-q-i-n/ 'el aventajado', equivalente de <yalliknin $>$ /yalli-q-ni-n/.

Nótese ahora que las formas modernas de expresiones como $<$ huc inca $>$, <pusac inca $>$, por un lado, y < soctanca $>$ y $<$ chunganca $>$, por el otro, se dan como /huk-ni-nka/, /pusaq-ni-nka/, /suqta-nka/ y /chunka-nka/, respectivamente, donde se observa claramente que las bases numerales (o en buena cuenta cualquier base nominal) acabadas en consonante requieren del morfo vacío -ni obligatoriamente. Y ocurre, conforme vimos, que este elemento aparece justo en el mismo casillero que ocupaba la /i/ de <inca>, con la cual se podía conmutar exactamente. Ello prueba definitivamente que la /i/ de <inca $>$ no formaba parte del elemento postpuesto -en verdad sufijo, digámoslo de una vez-, y que, por consiguiente, tenía el mismo estatus que el de un morfo vacío, a menos que se quiera decir que la /i/ de -ni es la misma de <inca $>$, en cuyo caso saldría sobrando *-n, que no sabríamos decir qué morfema es. Con lo que queda suficientemente demostrado el error de conmutación morfológica en que incurre el colega Itier, al no advertir la función de linker del elemento /i/ de su <inca>, burlado por el espejismo de la forma en que es presentado el morfema distributivo en las fuentes coloniales, que lo asemejaba a la palabra <inca> que, además, según se vio, no es sino resultado de la opción normativa de los quechuistas del Tercer Concilio en favor de $<$ ynca $>\sim<$ inca $>$, proscribiendo la forma bastardizada $<$ ynga $>\sim<$ inga $>$.

Por lo demás, el error de no haberse detectado en el quechua la existencia del morfo vacío $-i$, reemplazado posteriormente por $-n i$,

hoy solo se aceptan estas últimas formas, o sea /quyllur-ni-yuq/, /yawar-ni-yuq/ y / sipas-ni-yuq/, respectivamente. 
es algo que no parece haber llamado directamente la atención de los quechuistas, pues ni los lingüistas contemporáneos Parker y Torero, ni menos quienes han tenido mayor contacto con los tratados coloniales de la lengua, parecen haber tomado nota de su existencia. Peor aun, en el análisis de formas agentivas posesivas, tan productivas en los diccionarios coloniales, tales como <achuraqquey $>$ /achuraq-i-y/ 'el que me da la porción', <atauchaquey>/ataw-cha-q-i-y/ 'el que me es ocasión, o ayuda para tener dicha', <ñaupaqqueypi> /ñawpa-q-i-y-pi/ 'enfrente de mi', etc., y que ahora son desusadas, habiendo quedado en la actualidad algunas reliquias como */marq'aq-i-n/ 'padrino' o */kama-q-i-n/ 'espíritu' o 'ánimo', mal analizadas y peor identificadas como $* /$ marq'a-qi-n/ y $* /$ kama-qi-n/, respectivamente, aislando un supuesto sufijo ${ }^{*}-q i$ (ver, por ejemplo, en Cusihuamán 1976: cap. 7, \$7.22.8), se perdió definitivamente la pista de la existencia del morfo vacío $-i$. Lo que a su vez dio lugar a la identificación errática del falso morfema *-qi, considerado como "sufijo insólito", nada menos que por alguien que trabajó medio siglo con documentos coloniales, como fue el caso de Gérald Taylor (2000: 60), generoso amigo que nos dejara recientemente; y peor aun por Julio Calvo, aunque en este caso no sorprenda, como cuando analiza $<$ camaquen > como conteniendo los sufijos "Agentivo + Enfático o Validador [sic!] (-qi-n)" (Calvo 2013: I, 42). Para remate, como era de esperarse, este mismo autor analiza nuestro sufijo numeral distributivo como -inkal -inkanka, al igual que Itier y los gramáticos coloniales. Resulta realmente inesperado, por no decir ingenuo, cómo personas consideradas lingüistas o filólogos, veteranas en algunos casos, puedan caer en semejante análisis desastrado de los datos. Para ello solo tenemos una respuesta: y es que a desencuentros como el mencionado conduce el mal oficio de practicar una lingüística desmemoriada u olvidadiza, es decir ajena a toda información proveniente del análisis diacrónico de las estructuras de una lengua, en el presente caso del quechua. ${ }^{16}$

\footnotetext{
16 Que los autores nombrados no superaron el empantanamiento descriptivo en el que se sumergieron lo prueba el hecho de que el Anónimo, precisamente al presentar el para-
} 


\subsection{Obliteración de $-i$ en favor de -ni}

Debemos decir aquí que todo lo señalado sobre el uso del morfo vacío $-i$ en la prehistoria del quechua, previo al de $-n i$, ya lo habíamos adelantado en un artículo que publicamos hace un decenio (Cerrón-Palomino 2010), pero tal parece que ni Calvo ni Itier se enteraron de su existencia, o si tuvieron noticia de él, es probable que no le dieran la importancia debida, cuando en verdad les habría sido de provecho para no caer en inadvertencias analíticas como las que acabamos de ver. En el mismo trabajo aventurábamos la hipótesis de la posible adopción del elemento -ni por parte del quechua, con alta probabilidad procedente del aimara, en etapas muy antiguas, pero previas a su fragmentación posterior. Gracias a los modelos interpretativos que se han venido formulando en relación con el fenómeno de convergencia inicial ocurrido en sus etapas de pre-protolenguas (Adelaar 2010, Muysken 2012), hoy es posible sostener que dicho proceso debió darse cuando tales entidades ocupaban territorios geográficamente contérminos en la sierra centro-peruana en tiempos del Formativo Tardío (200 a. C.-200 d. C.). En dicho período el pre-protoquechua habría sido adoptado como segunda lengua por los pueblos que hablaban el pre-protoaimara, y como resultado de ello aquella entidad primordial remodelaría algunas de sus estructuras morfo-sintácticas, a la par que el pre-protoaimara se habría beneficiado con la incorporación de préstamos léxicos masivos provenientes de aquel (Adelaar 2010, 2020).

Ahora bien, en relación con la temprana adopción de -ni en el quechua, el mejor argumento que podría aportarse es el hecho de que, hasta donde sabemos, ningún dialecto de la lengua es ajeno a su

digma de las formas agentivas (= "participio de presente") posesivas del tema <rura-q> 'hacedor', enlista las terminaciones <quey> 'mío', <queyqui> 'tuyo', <quen> 'suyo', etc., como si fueran elementos indesligables, para formar las expresiones respectivas de $<$ ruraquey $>$ /rura-q-i-y/ 'mi hacedor', <ruraqueyqui $>$ /rura-q-i-yki/ 'tu hacedor' y $<$ ruraquen> /rura-q-i-n/ 'su hacedor', respectivamente (Anónimo [1586] 2014: 373-374). Por lo visto, los colegas citados no pudieron superar el problema de naturaleza hipoanalítica de los gramáticos coloniales. 
empleo auxiliar dentro del sistema flexivo nominal cuando la base por flexionarse acaba en consonante, justamente en el contexto en que previamente se echaba mano de $-i$, conforme se vio. Lo propio podría decirse, según se pudo apreciar también, de su concurso en la derivación de los numerales distributivos. En ambos casos, como se dijo, el recurso a -ni es de orden estructural, y, por consiguiente, obligatorio. No ocurre lo mismo, sin embargo, con su empleo en otros contextos, en los cuales su participación es opcional, y hay dialectos que simplemente no lo requieren. Tal es el caso, por ejemplo, del quechua ancashino, en el que la derivación de formas posesivas con el sufijo -yuq, cuando la base acaba en consonante, no requiere del auxilio de $-n i$ (Parker 1976: cap. 4, $\mathbb{S}$ 4.13.12). El hecho de que haya dialectos que no han generalizado el empleo de $-n i$ en contextos en los cuales su uso resulta obligatorio por razones estructurales, es un buen indicador de que la extensión de su empleo solo se dio una vez que la entidad matriz fue escindiéndose, de manera que su universalización ya no alcanzó a cubrir a todas las variedades que emanaron de ella.

Resta por elaborar el argumento en favor de la fuente aimara del morfo vacío -ni. Al respecto, según lo sugerimos en el artículo mencionado, creemos que dicho elemento habría tenido como base el posesivo aimara -ni que funciona como operador en la formación de los numerales de decena, como por ejemplo en tunka maya-ni 'once' (lit. 'diez con uno'), pataka paya-ni 'ciento dos', pataka kimsa chunka pusi-ni 'ciento treintaicuatro', etc., equivalentes a chunka buk-ni-yuq, pachak iskay-ni-yuq y pachak kimsa chunka tawa-yuq, respectivamente, con ejemplos propios del quechua sureño. Como puede verse, en las decenas cuya base acaba en consonante, se inserta $-n i$, redundantemente, pues - $y n q$ tiene el mismo significado aditivo. El vaciamiento o blanqueo de significado de -ni, cuya forma tiene ahora valor puramente eufónico, habría contribuido a su generalización como linker en las estructuras nominales del quechua mencionadas en párrafos precedentes. Recalquemos, sin embargo, que el recurso a dicho elemento no llegó a generalizarse en todos los dialectos, ni siquiera dentro del 
sistema numérico, como es el caso del quechua ancashino, en el que los múltiplos de diez se forman por simple yuxtaposición: cbunka buk 'once', pachak ishkay 'doce', etc. (Parker 1976: \$4.2.5), siendo este procedimiento una de las alternativas, aparte del recurso a -wan en lugar de -yuq, ya mencionada por el primer gramático quechua, como en <chunga sucguan $>$ 'once' o <chunga iscayguan $>$ 'doce', pero siempre alternando con las formas con <-nioc> (Santo Tomás ([1560] 1995: cap. 20). ${ }^{17}$

\subsection{Lexicalización inusitada}

Volviendo ahora a la propuesta inusitada del colega Itier de postular el significado básico de la raíz léxica <inca> a partir de la información gramatical de una supuesta postposición *<-inca $>,{ }^{18}$ diremos que, además de carecer de base empírica, conforme se vio, resulta peregrina desde el momento en que choca violentamente con uno de los postulados establecidos dentro de la ciencia lingüística contemporánea, concretamente uno de los universales que trazan la

17 Faucet Pareja (2015), en su vocinglera reconstrucción del sufijo adjudicativo quechua $-y u q$, no solo demuestra no haber reparado en la existencia del antiguo morfo vacío $-i$, sino que tampoco parece haber entendido la adopción restringida, si se quiere trunca, del morfo vacío - ni por el quechua; y así, pretende "refutar" nuestra propuesta de su uso con valor tradicional o eufónico, recurriendo a ejemplos del ancashino y del huanuqueño, cuando en verdad no hacía falta redundar sobre su actuación no generalizada en vista de los ejemplos aportados por el dominico. Por lo demás, su forzada y arbitraria postulación de *-nyuq como el étimo de -yuq, y que según él sería una "nueva hipótesis" que permitiría "retroceder aún más en la historia” (2015: 105) del proto-quechua (sic), nos parece un ejercicio aeróbico desprovisto de toda base empírica, es decir un sacrificio del objeto de estudio en provecho de seudo constructos formales hueros a los que suele ser proclive. El hecho es que, sincrónicamente, todavía hay dialectos del quechua que permiten postular el pre-proto-radical verbal **yu-con el significado de 'tener', en compuestos verbales sintácticamente congelados, y que daremos a conocer en algún momento.

18 Que sepamos, no es nuestro autor el primero en postular hipótesis semejante. La primera en hacerlo, sin las disquisiciones semánticas de aquel, fue la colega ecuatoriana Ileana Almeida, en la década del 90 del siglo pasado, en un artículo que lamentablemente no hemos podido ubicar, ni siquiera con el auxilio de la propia autora, quien nos dejó desconcertados al respondernos que no se acordaba dónde lo había publicado. Que Ileana Almeida haya propuesto semejante interpretación no nos sorprende, pero que lo haya hecho César acabó por dejarnos realmente perplejos. 
“trayectoria diacrónica regular y sistemática” de los procesos de gramaticalización o génesis de los elementos gramaticales de una lengua. Según los postulados de la disciplina, el recorrido diacrónico en los procesos de gramaticalización, particularmente tratándose de lenguas sufijantes (como es el caso del quechua), puede formularse esquemáticamente del siguiente modo: palabra $>$ enclítico $>$ sufijo, y no al revés (Hopper 1990, Bybee y otros 1990). Lo que equivale a decir que los sufijos, antes de ser tales, fueron enclíticos, y éstos a su vez surgieron de palabras o radicales lexemáticos mediante procesos internos complejos de desgaste formal-semántico y pérdida de autonomía. Lo que a su vez quiere decir, en el caso que estudiamos, y de aceptarse la hipótesis examinada, que el significado del sufijo *<-inca $>$, de función distributiva, debía rastrearse a partir de la raíz léxica <inca>, que designaba un linaje especial, y no invirtiendo los roles, como lo hace Itier. ${ }^{19}$ Sobra señalar que cualquier intento de relacionar o asociar ambos elementos desde el punto de vista semántico e histórico, como lo hace el autor (Itier 2019: 148), incluso al margen de la tendencia universal mencionada, no tiene asidero que valga. Además, apoyarse en abono de su tesis invocando los casos de los sufijos gramaticalizados -kama 'limitativo' y

19 En verdad este procedimiento no es novedoso en el autor, ya que fue el mismo que siguió para postular el significado de la raíz verbal pre-proto-quechua **ya- (en verbos de movimiento del tipo $y a-y k u$ - 'entrar', $y a-r q u$ - 'salir', etc.), manifiesto, según el autor, en el verbo actual yaĉa- 'saber' (yacha-, en el quechua sureño), a partir del actual sufijo verbalizador $-y a$, que "indica el paso de un estado a otro, es decir el cruzar un límite cualitativo” (Itier 1993: 153-154). Todo ello, sin prestar mucha atención al hecho de que el quechua-huanca es uno de los pocos dialectos que registra la raíz ya-, con el significado prístino de 'saber', como en ya-y 'juicio, razón', forma nominalizada, de manera que $y a-y$-ni-yur es una persona entendida, con juicio y razón, mientras que ya-şza es sinónimo de 'persona sabia' (proto-radical presente también en **ya-rpa- 'recordar'). No obstante haberle proporcionado estos datos, el colega siguió adelante con su propuesta, de manera que para él *ya-ĉa- significaría el tránsito de 'ir a saber', cuando en verdad habría significado literalmente 'llegar a saber o conocer' (donde ${ }^{*} * \hat{c} a-$ es el proto-verbo 'llegar'). Señalemos, de paso, que Emlen y Dellert (2020), en su interesante y tanteador estudio acerca de la génesis de las raíces polimorfémicas del proto-quechua, se ocupan, solo al pasar, del proto-verbo 'ya- 'ir' ( nota 8 del artículo), sin mencionar para nada a su homófono *ya- 'saber', de cuyo uso perifrástico, al igual que el de *ya- 'permanecer, establecerse' ( "ya-ĉa- 'llegar a establecerse'), en ambos casos evidenciado por la morfosintaxis congelada del quechua, nos ocuparemos en otra ocasión. 
-rayku 'causal', a los cuales podríamos agregar -pura 'interactivo', no viene al caso, ya que para ellos el entronque fonético-fonológico con sus formas léxicas respectivas resulta transparente, e igualmente evidente el enlace semántico entre ambos. En suma, creemos haber demostrado que la hipótesis del colega no reúne las condiciones mínimas de adecuación empírica, no solo en términos del examen sincrónico efectuado con el material documental examinado, sino sobre todo porque viola uno de los principios universales que rigen la génesis y la formación de palabras, amplia y empíricamente establecidos dentro de la lingüística contemporánea. Por lo demás, como se dijo, el extravío de la propuesta parte de un error inicial consistente en postular una etimología nativa para un lexema de filiación claramente ajena a la lengua, motivado, a su turno, por responder a una actitud de claro negacionismo de toda impronta puquina en el quechua.

\section{Cuestiones interpretativas}

Desde el punto de vista de la interpretación semántica e histórica del nombre <inca $>$, la propuesta inicial de Itier cuestiona el concepto establecido por la historiografía incaica según el cual los incas prehispánicos habrían constituido un grupo étnico privilegiado, una casta hereditaria de linaje nobiliario liderada por el <inca $>$, el máximo gobernante de su clase. Esta concepción del <inca > como personaje y de su grupo como entidad socio-política sería para el autor un constructo institucional artificialmente elaborado, como resultado de una malinterpretación de los usos y registros acríticos del término por parte de los historiadores iniciales y de los estudiosos modernos, a menudo prejuiciados por nociones exógenas de corte eurocéntrico. De este modo, la noción de la categoría de <inca> conceptualizada dentro de la historiografía moderna, muy lejos de reflejar el concepto prístino prehispánico que se quiere postular, tendría un origen más bien colonial. En tal sentido, creemos entender que la revisión drástica del significado de <inca> que el estudioso francés se propone desarrollar está en consonancia 
con el tipo de estudios de corte filológico e interpretativo ofrecidos previamente por Pierre Duviols y el autor en relación con las manipulaciones que realizaron los evangelizadores al adecuar el léxico religioso de los himnos quechuas al servicio del dogma judeo-cristiano, desvirtuándolos y disociándolos de su verdadero mensaje nativo (Duviols e Itier 1993). Y si bien, como lo hemos reconocido públicamente (por ejemplo, Cerrón-Palomino 2018: \4.3), nos hemos apurado en aplaudir dicha labor de depuración léxico-semántica del quechua colonial, por basarse en el análisis crítico y riguroso de la documentación lexicográfica respectiva (ver, sin embargo, nuestra nota 16), tenemos la sensación de que el autor ha venido descuidando, en trabajos recientes, el rigor con que abordaba el examen filológico e histórico de los términos y conceptos andinos estudiados, cayendo inevitablemente en lamentables contradicciones, como lo señalamos en Cerrón-Palomino (2021b), y en el caso presente del que nos estamos ocupando.

Pues bien, no entraremos a discutir todo el extenso ejercicio retórico elaborado por el autor intentando demostrar vanamente el carácter según él postizo, cuando no distorsionado, del concepto de $<$ inca $>$ y de lo incaico, alegando ser producto de una interpretación que no se ajustaría al sentido originario del término. Nos limitaremos, más bien, a poner en cuestión el argumento medular de orden filológico e histórico en el que se apoya buscando ofrecernos una redefinición sustancial del concepto y sus ramificaciones en función de una caracterización semánticamente más prístina de su naturaleza institucional dentro de la organización socio-política del incario. ¿En qué consiste entonces la reconceptualización del concepto de <inca> propuesta por el colega Itier? Según sus palabras, la noción conceptual más ajustada y apropiada sería la que se infiere del análisis cuidadoso de la evidencia lingüística y filológica del material léxico-gramatical examinado, en este caso el de la palabra <inca > y el de la postposición <inca $>$, para el autor claramente relacionados semántica y etimológicamente. De esta manera, "precedido de un adjetivo de cantidad este sustantivo [el de la postposición <inca>] designaba una unidad separada de un conjunto 
y constituida por dicha cantidad de elementos ("porción de uno», «porción de dos», etc.)"; y, "utilizado como sustantivo «libre» o después de un nombre propio, significaba '(alguien) separado (del resto de la sociedad)'” (Itier 2019: 149, énfasis agregado). En cualquier caso, el significado fundamental que unía a ambos referentes (no importando que uno sea de orden léxico y el otro más bien gramatical) habría sido, vagamente a nuestro modo de ver, el de "(algo o alguien) separado” (Itier 2019: 149), es decir designaría a una orden o desagregado social jerárquicamente importante, distinto al resto del común de los miembros de la sociedad. En palabras del autor:

la información histórica [...] acerca de los incas anteriores a la colonización eran hombres separados del común de los adultos trabajadores (o batun runa [sic] 'adulto(s)'), porque no entraban en relaciones de cooperación laboral con ellos, sino que se dedicaban a la guerra y a la administración (Itier 2019: 149).

Noción, como se puede apreciar, indeterminada y genérica, que en nada enriquece o precisa el concepto tradicional del término, entendido este como grupo étnico de privilegio y de poder distinto del resto de la sociedad. Ya se demostró ampliamente, por lo demás, cómo el concepto distributivo de 'separación' o 'segregación' de un conjunto que el autor considera parte medular del significado de <inca $>$ es más bien de orden gramatical (propio del sufijo, considerado como postposición) y no léxico, pues de ningún modo proviene, como debiera, de su forma léxica autónoma, cuya noción original de grupo étnico resulta ahora reinterpretada o parafraseada, como resultado del traslape arbitrario de un significado ajeno a ella, que el autor hace de manera forzada.

Habiendo demostrado que la raíz léxica <inca>, de muy posible origen puquina, nada tiene que ver con el sufijo distributivo $<-$ inca $>$ (desprovisto de autonomía solo en la escritura tradicional de los primeros gramáticos coloniales), de filiación quechua, todo el argumento de naturaleza documental y etnográfica elaborado por el autor en abono de su hipótesis cae por su propio peso, y no sólo 
por razones estrictamente histórico-lingüísticas y filológicas, sino también por el manejo teórico equivocado que se hace del concepto de la trayectoria diacrónica de los procesos de gramaticalización, haciendo prevalecer el significado de un elemento gramaticalizado - sufijo o postposición - al de un lexema gramatical etimológicamente ajeno. Como se dijo, nuestra impresión es que todo el ejercicio profuso y retórico desplegado por el autor en su trabajo es el resultado de su afán por querer explicar la prehistoria incaica sólo a partir del quechua, siguiendo la corriente de opinión que hemos caracterizado como la del "quechuismo primitivo", ignorando la naturaleza pluriglósica del mundo prehispánico en el que dicha lengua fue tributaria beneficiada (algo así como un latín indiano frente al griego) por el aporte léxico-semántico y gramatical nada desdeñables del aimara y del puquina.

\section{A manera de resumen}

En lo que sigue intentaremos resumir algunos de los puntos fundamentales de la discusión desarrollada en las secciones precedentes que consideramos importantes destacar.

En primer lugar, en cuanto a la filiación del término <inca>, nos ratificamos en nuestra propuesta de atribuirle una procedencia puquina altamente probable, como parte del legado léxico institucional de esta lengua dentro del quechua, en particular dentro del campo semántico de los nombres y epítetos, la mayoría de ellos privativos de la casta imperial.

En segundo término, postulamos la forma *inqa [enqa] como el étimo de la palabra, apoyados en las evidencias de orden documental y etnográfico en favor de la forma de relicto que aún subsiste en el léxico mágico-religioso manejado por los pastores de las regiones altas del Cuzco, quedando demostrado el carácter artificial de la versión canónica de la palabra <inca>, como resultado de la normalización de <ynga>, voz propia de la "lengua general” difundida y promovida por los soberanos cuzqueños antes de la llegada de 
los españoles, y posteriormente instituida por los traductores de la Doctrina Cristiana del Tercer Concilio Limense (1582-1583).

En tercer lugar, queda demostrada la inviabilidad de la propuesta etimológica revisionista del colega César Itier en vista de que la forma que postula, otorgándole a su constructo de *inka una filiación quechua, carece de sustento empírico tanto sincrónico como diacrónico, amén de filológico, habiendo sido formulada además a espaldas de, o subestimando, conceptos básicos no solo de la morfosintaxis quechua, sino también de los principios universales lingüísticos que gobiernan los procesos de gramaticalización.

En cuarta instancia, y como consecuencia de lo anterior, la nueva lectura semántica de <inca $>$ postulada por el autor resulta igualmente arbitraria por partir del traslape gratuito que hace del significado gramatical de una postposición al de un lexema de forma y significado autónomos como fue seguramente *inqa, forzando los referentes dispares de los elementos asociados de manera gratuita.

En quinto lugar, todo el esfuerzo realizado por el autor para armar su propuesta, internándose en disquisiciones de orden histórico y etnográfico, en desmedro de los aspectos lingüístico-filológicos y diacrónicos de la materia desatendidos, no convence como alternativa de interpretación de <inca> en cara a la noción establecida que se tiene del término dentro de la historiografía incaica; en todo caso, el examen de los roles y funciones que el investigador destaca a partir de los usos de la palabra en las fuentes estudiadas, resultan enteramente aleatorios y de ningún modo contradicen el concepto tradicional que se tiene de ella.

En sexta y última instancia, tenemos la impresión de que el afán de nuestro colega por persistir en la explicación interna, es decir nativa al quechua, de los términos institucionales del incario, lo conduce lamentablemente a postular etimologías librescas, como la del presente caso, y para lo cual, lejos de ceñirse a la evidencia lingüística y filológica básica, se prefiere la elaboración de todo un aparato argumentativo que flota en el aire, pero que desorienta y confunde a los científicos sociales, a menudo asustadizos, cuando no sueltos de huesos o audaces, en el manejo de las fuentes lingüísticas. En tal 
sentido, dejar en manos de los científicos sociales, especialmente historiadores y arqueólogos, la tarea que les encarga el autor para que intenten verificar la propuesta lanzada tendría el efecto dañino de desorientarlos más de lo que habitualmente ya están en materia de interpretación crítica del léxico institucional del incario.

\section{Referencias bibliográficas}

AMLQ (Academia Mayor de la Lengua Quechua)

1995 Diccionario quechua-español/ español-quechua. Cuzco: Municipalidad del Cuzco.

AdelaAR, Willem F.H.

2006 "The Quechua Impact in Amuesha, an Arawak Language of the Peruvian Amazon". En Grammars in contact: A crosslinguistic typology. Eds., Alexandra Aikhenwald y Robert Dixon. Oxford/ New York: Oxford University Press, 290312.

AdelaAr, Willem F.H.

2010 "Modeling convergence: Towards a reconstruction of the history of Quechua-Aymaran interaction". Lingua. 122, 5, 461-468.

AdeLAar, Willem F.H.

2020 "Reconstruction beyond proto-languages in the Middle Andes". Cadernos de Lingüística. 1, 1, 1-13.

Anónimo (Blas Valera)

[1586] 2014 Arte, y vocabvlario en la lengva general del Perv llamada quichua, y en la lengua española. Edición modernizada e interpretada de Rodolfo Cerrón-Palomino. Lima: Instituto Riva Agüero, PUCP.

Araníbar, Carlos (ed.)

[1615] 2015 Versión modernizada y notas de la edición de la Nueva crónica y buen gobierno de Huaman Poma de Ayala. Tomo III. Lima: Biblioteca Nacional del Perú.

ARguedas, José María

1983 Los ríos profundos. En Obras completas. Tomo III. Lima: Editorial Horizonte, 11-203. 
BERTONIO, Ludovico

[1612] 1984 Vocabolario de la lengua aymara. Cochabamba: CERES e IFEA.

Betanzos, Juan Diez de

[1551] 2015 Suma y narración de los incas. Nueva edición de Francisco

Hernández Astete y Rodolfo Cerrón-Palomino. Lima: Fondo Editorial PUCP.

Bybee, Joan L. y otros

1990 "On the Asymmetries in the Affixation of Grammatical Material”. En Studies in diachronic typology for Joseph Greenberg. Eds., William Croft, Suzanne Kemmer y Keith Denning. Amsterdam: John Benjamins, 1-42.

Calvo Pérez, Julio

2013 "El Lexicón de Domingo de Santo Thomás: una aproximación lingüística”. Estudio preliminar a la edición del Lexicón o vocabulario de la lengua general del Perú. Tomo I. Lima: Fondo Editorial de la USMP, 27-60.

Cerrón-Palomino, Rodolfo

1997 "El Diccionario quechua de los académicos: cuestiones lexicográficas, normativas y etimológicas”. Revista Andina. 29, 1, 151-205.

Cerrón-Palomino, Rodolfo

2008a Quechumara: estructuras paralelas del quechua y del aimara. La Paz: PROEIBANDES-PLURAL.

Cerrón-Palomino, Rodolfo

2008b Voces del Ande. Ensayos sobre onomástica andina. Lima: Fondo Editorial de la PUCP.

Cerrón-Palomino, Rodolfo

2010 "Sobre el morfo vacío -ni del quechua". En Linguistics and Archaeology in the Americas. The Historization of Language and Society. Volumen de Homenaje al Prof. Willem Adelaar. Eds., Eitne Carlin y Simon van de Kerke. Leiden/ Boston: Brill, 177-189.

Cerrón-Palomino, Rodolfo

2013a Las lenguas de los incas: el puquina, el aimara y el quechua. Frankfurt am Main: Peter Lang GmbH. 
Cerrón-Palomino, Rodolfo

2013b Tras las huellas del Inca Garcilaso. El lenguaje como hermenéutica en la comprensión del pasado. Boston: Latinoamericana Editores/ CELACP.

Cerrón-Palomino, Rodolfo

2017 "El quechua «del ynga» según testimonio de los primeros cronistas”. En Literaturas orales y primeros textos coloniales. Tomo I. Coords., Juan Carlos Godenzzi y Carlos Garatea. Lima: Fondo Editorial PUCP/ Ministerio de Educación, 83-103.

Cerrón-Palomino, Rodolfo

2018 "Lingüística histórica y Filología en el área andina: encuentros y desencuentros”. Revista Andina. 56, 101-128.

Cerrón-Palomino, Rodolfo

2019 "La tesis del quechuismo primitivo y su efecto distorsionado en la interpretación del pasado prehispánico". En El estudio del mundo andino. Ed., Marco Curatola. Lima: Fondo Editorial PUCP, 177-186.

Cerrón-Palomino, Rodolfo

2020 "La presencia puquina en el aimara y en el quechua: aspectos léxicos y morfosintácticos”. Indiana, 37,1, 129-153.

Cerrón-Palomino, Rodolfo

2021a “Apéndice I". En Materialidad, memoria y lenguaje en la Relación de las fábulas y ritos de los Incas (1575) de Cristóbal de Molina. Eds., Rodolfo Cerrón-Palomino y Francisco Hernández. Berlín: Peter Lang. Por aparecer.

Cerrón-Palomino, Rodolfo

2021b "Otra vuelta de tuerca: la etimología de <quechua> en quechua y aimara”. Indiana. Por aparecer.

Cieza de Leon, Pedro de

[1551] 1985 Crónica del Perú, Segunda Parte. Lima: Fondo Editorial de la PUCP.

Cusihuamán Gutiérrez, Antonio

1976 Gramática quechua: Cuzco-Collao. Lima: Instituto de Estudios Peruanos/ Ministerio de Educación. 
Duviols, Pierre y César ITIER

1993 "Estudio etnohistórico y lingüístico". Introducción a la edición de la Relación de antigüedades deste reyno del Pirú, de Joan de Santa Cruz Pachacuti Yamqui Salcamaygua. Cuzco: C.E.R.A. Bartolomé de Las Casas.

EmLen, Nicholas Q. y Johannes Dellert

2020 "On the Polimorphemic Genesis of Some Proto-Quechua Roots: Establishing and Interpreting Non-Random Form/ Meaning Correspondences on the Basis of a Cross-Linguistic Polysemy Network". Diachronica. 37, 3, 11-37.

Faucet Pareja, Carlos Alberto

2015 "Historia del sufijo tenencial del quechua: reconstrucción y nuevas hipótesis”. Letras. 86, 123, 105-124.

Flores OchoA, Jorge A.

1977 "Enqa, enqaychu, illa y khuya rumi”. En Pastores de la puna. Uywa-michik punarunakuna. Comp., Jorge Flores Ochoa. Lima: Instituto de Estudios Peruanos, 210-237.

Flores OchoA, Jorge A.

2002 “El Inka histórico es el Enqa contemporáneo”. En El hombre y los Andes. Homenaje a Franklin Pease G. Y. Tomo II. Eds., Javier Flores Espinoza y Rafael Varón Gabai: Lima: IFEA/ Banco de Crédito del Perú, 611-616.

Garcilaso de la Vega, Inca

[1609] 1943 Comentarios Reales de los Incas. Buenos Aires: Emecé Editores S.A.

Gonçález Holguín, Diego

[1607] 1975 Gramatica y arte nveva de la lengva general de todo el Perv, llamada lengua qquichua, o lengua del Inca. Cabildo Vaduz-Georgetown: Franz Wolf, Heppenheim a.d.B. Edición facsimilar.

Gonçález Holguín, Diego

[1608] 1952 Vocabolario de la lengva general de todo el Perv llamada lengva qquichua o del Inca. Lima: UNMSM.

Guaman Poma de Ayala, Felipe

[1615] 1936 Nueva corónica y buen gobierno. Paris: Institut d’Ethnologie. 
Hopper, Paul J.

1990 "Where do words come from?" En Studies in diachronic typology for Joseph Greenberg. Eds., William Croft, Suzanne Kemmer y Keith Denning. Amsterdam: John Benjamins, 151160.

ITIER, César

1993 “Estudio y comentario lingüístico”. En Pachacuti [1613] 1993: 129-178.

ITIER, César

2019 “QQué significaba el término inka?”. Bulletin de l'Institut d'Études Andines. 48, 2, 135-149.

Molina, Cristóbal de

[1575] 2021 Relación de las fábulas y ritos de los incas. Edición crítica de Rodolfo Cerrón-Palomino y Francisco Hernández Astete. Frankfurt am Main: Peter Lang/ PUCP.

Muysken, Pieter

2012 "Modelling the Quechua-Aymara Relationship: Structural Features, Sociolinguistic Scenarios and Possible Archaeological Evidence". En Archaeology and Language in the Andes. A Cross-Disciplinary Exploration of Prebistory. Eds., Paul Heggarty y David Beresford-Jones. London: The British Academy, Oxford University Press, 85-109.

Pachacuti, Joan de Santa Cruz

[1613] 1993 Relación de antigüedades deste reyno del Piru. Estudio etnohistórico y lingüístico de Pierre Duviols y César Itier. Cuzco: I.F.E.A. y C.E.R.A. Bartolomé de Las Casas.

PARker, Gary J.

1976 Gramática quechua: Ancash-Huailas. Lima: Instituto de Estudios Peruanos y Ministerio de Educación.

PÉrez Silva, Jorge Iván

2011 "Las innumerables vocales del quechua". En Estudios sobre lenguas andinas y amazónicas. Homenaje a Rodolfo CerrónPalomino. Eds., Willem Adelaar, Pilar Valenzuela y Roberto Zariquiey. Fondo Editorial PUCP, 211-231. 
Polo Ondegardo, Juan

[1584-1585] 1985 “Tratado de los errores y svpersticiones delos Yndios”. En Tercer Concilio Limense [1584-1585]. 1985, 265-283.

SANChO de La Hoz, Pedro

[1534] 1968 "Relación para su majestad”. En Biblioteca Peruana. Primera Serie. Tomo I. Lima: Editores Técnicos Asociados S.A., 277343.

SAnto Tomás, Domingo de

[1560] Grammatica o arte de la lengua general de los Indios de los 1994a Reynos del Peru. Edición facsimilar, transliteración y estudio preliminar de Rodolfo Cerrón-Palomino. Madrid: Ediciones de Cultura Hispánica.

SAnTo Tomás, Domingo de

[1560] Lexicon o vocabulario de la lengua general del Peru. Edición 1994b facsimilar y nota preliminar de Rodolfo Cerrón-Palomino. Madrid: Ediciones de Cultura Hispánica.

SANTO Tomás, Domingo de

[1560] 1995 Grammatica o arte de la lengua general de los indios del Perú. Edición, estudio introductorio, y notas de Rodolfo CerrónPalomino. Cuzco: C.E.R.A. “Bartolomé de Las Casas”.

SZEMIÑSKI, Jan

2009 Un ejemplo de larga tradición bistórica andina. Libro $2^{\circ}$ de las Memorias antiguas historiales y políticas del Perú redactado por Fernando de Montesinos. Madrid: Iberoamericana/ Vervuert.

TAYLOR, Gérald

2000 Camac, Camay y Camasca. Cuzco: C. E. R. A. Bartolomé de Las Casas/ IFEA.

Tercer Concilio Limense

[1584-1585] Doctrina Christiana, y catecismo para instrvccion de los Indios 1985 [...] con un confessionario, y otras cosas [...]. Edición facsimilar. Madrid: Consejo Superior de Investigaciones Científicas.

Torero, Alfredo

1994 "El idioma particular de los incas". En Estudios de lengua y cultura amerindias I. Ed., Julio Calvo Pérez. Valencia: Universidad de Valencia, 231-240. 
Uhle, Max

[1910] 1969 “Los orígenes de los incas”. En Estudios de Historia Incaica. Lima: UNMSM, 29-69.

Zárate, Agustín de

[1555] 1995 Historia del descubrimiento y conquista del Perú. Lima: Fondo Editorial de la PUCP.

Zuidema, Tom R.

2010 El calendario inca. Tiempo y espacio en la organización ritual del Cuzco. La idea del pasado. Lima: Fondo Editorial del Congreso del Perú/ Fondo Editorial PUCP.

Recepción: 14/01/2021

Aceptación: 15/02/2021 